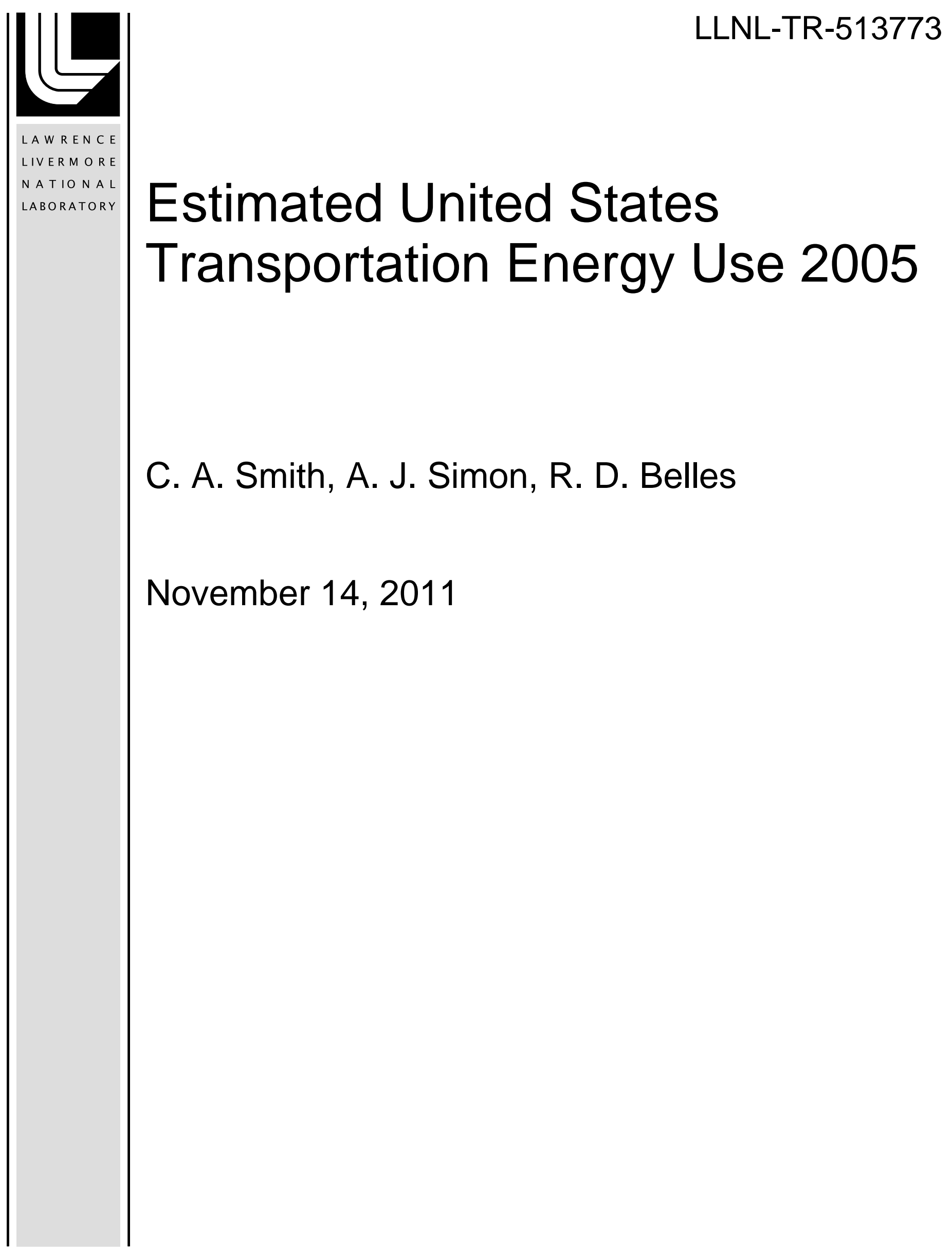


This document was prepared as an account of work sponsored by an agency of the United States government. Neither the United States government nor Lawrence Livermore National Security, LLC, nor any of their employees makes any warranty, expressed or implied, or assumes any legal liability or responsibility for the accuracy, completeness, or usefulness of any information, apparatus, product, or process disclosed, or represents that its use would not infringe privately owned rights. Reference herein to any specific commercial product, process, or service by trade name, trademark, manufacturer, or otherwise does not necessarily constitute or imply its endorsement, recommendation, or favoring by the United States government or Lawrence Livermore National Security, LLC. The views and opinions of authors expressed herein do not necessarily state or reflect those of the United States government or Lawrence Livermore National Security, LLC, and shall not be used for advertising or product endorsement purposes.

This work performed under the auspices of the U.S. Department of Energy by Lawrence Livermore National Laboratory under Contract DE-AC52-07NA27344. 


\section{Estimated United States Transportation Energy Use 2005 United States}

C.A. Smith, A.J. Simon, R.D. Belles

November 2011

Abstract
Introduction
Flow Chart
Analysis
Conclusion
References
Appendix




\title{
Estimated United States Transportation Energy Use: 2005
}

\author{
Clara A. Smith, A.J. Simon, Rich Belles \\ Lawrence Livermore National Laboratory
}

\begin{abstract}
A flow chart depicting energy flow in the transportation sector of the United States economy in 2005 has been constructed from publicly available data and estimates of national energy use patterns. Approximately 31,000 trillion British Thermal Units (trBTUs) of energy were used throughout the United States in transportation activities. Vehicles used in these activities include automobiles, motorcycles, trucks, buses, airplanes, rail, and ships. The transportation sector is powered primarily by petroleumderived fuels (gasoline, diesel and jet fuel). Biomass-derived fuels, electricity and natural gas-derived fuels are also used. The flow patterns represent a comprehensive systems view of energy used within the transportation sector.
\end{abstract}

\section{Introduction}

Lawrence Livermore National Laboratory (LLNL) has published flow charts (also referred to as "Sankey Diagrams") of important national commodities since the early 1970s. The most widely recognized of these charts is the U.S. energy flow chart (http://flowcharts.Inl.gov). LLNL has also published charts depicting carbon (or carbon dioxide potential) flow and water flow at the national level as well as energy, carbon, and water flows at the international, state, municipal, and organizational (i.e. United States Air Force) level. Flow charts are valuable as single-page references that contain quantitative data about resource, commodity, and byproduct flows in a graphical form that also convey structural information about the system that manages those flows. The flowchart can be read "left-to-right". Energy taken from the environment is refined into transportation fuels These fuels are distributed to vehicles, which convert the energy to propulsive work. That work is the fundamental service provided by the transportation sector.

This is the first presentation of detailed energy flow in the transportation sector of the United States economy. Data on transportation energy use is collected by the U.S. Department of Energy's Energy Information Administration (U.S. EIA) and the Department of Transportation's Bureau of Transportation Statistics (BTS). The primary data source for this report is Oak Ridge National Laboratory's Transportation Energy Data Book (TEDB, 2010), which is based largely on BTS and EIA data. Where TEDB did not have enough detail, U.S. EIA's Alternatives to Traditional Transportation Fuels (ATTF, 2008) served as a secondary reference. A handful of other statistics, as well as vehicle efficiencies and other conversion factors, were calculated from the other references listed in the bibliography. Because many transportation energy statistics are not published on an annual basis, this report is based on data for the year 2005, the most recent year for which a full accounting is possible. 
This flow chart of transportation energy usage and explanations of the calculations and assumptions utilized can be found at: http://flowcharts.Ilnl.gov. 


\section{Analysis}

This visualization of energy use in the transportation sector is based upon a "bottom-up" calculation of energy consumption for civilian consumption. Specific energy flows for which data is available are listed first, followed by flows and quantities which are calculated as residuals or summations. Every effort has been made to logically group energy flows by sector and fuel.

\section{Consumption of Refined Fuels:}

Energy use in the transportation sector is based on the consumption of refined fuels. In many cases, statistics for the consumption of these commodities in the transportation sector are readily available.

\section{Electricity:}

Electricity Production -> Automobiles

Light duty vehicles are reported to have consumed 3.6 million gasoline-equivalent gallons of Electricity or 0.45 trBTUs in 2005 (ATTF: Table C5, 2010). ${ }^{1}$ Because light duty vehicles are not described in further detail, the Electricity usage of 0.45 trBTUs by light duty vehicles is entirely attributed to Automobiles.

\section{Electricity Production -> Medium \& Heavy Trucks}

In 2005, Electricity use by medium duty vehicles is reported as 44 thousand gasoline-equivalent gallons or 0.0055 trBTUs and use by heavy duty vehicles (including buses) is reported as 1.6 million gasolineequivalent gallons or 0.20 trBTUs (ATTF: Table C5, 2010). As described below, Transit Buses used 530 thousand kilowatt hours of electricity, or 0.00069 trBTUs, in 2005 by another source (TEDB: Table A.3, 2010). The Electricity attributed to medium duty and heavy duty vehicles not used as fuel by Transit Buses is attributed to Medium \& Heavy Trucks, which is equivalent to $0.20 \mathrm{trBTU}$ s of energy.

\section{Electricity Production -> Transit Buses}

The energy from Electricity Production used by Transit Buses is reported as 0.00069 trBTUs in 2005 (TEDB: Table A.3, 2010).

\section{Electricity Production -> Pipeline}

The pipeline sector consumes electricity at some pumping and compression stations. The energy from Electricity Production used by Pipeline is calculated to be 27 trBTUs in 2005 (TEDB: Table A.11, 2010). ${ }^{2}$

\section{Electricity Production -> Passenger Rail}

The energy from Electricity Production used by Passenger Rail is calculated to be 66 trBTUs in 2005 (TEDB: Tables A.13-A.15, 2010).

\footnotetext{
${ }^{1}$ Over $90 \%$ of the estimated number of electric vehicles in service in 2008 are "Low Speed Vehicles" (ATTF: Table V5, 2010), which are assumed to fall in the class of Automobiles. As this flow is relatively small and the remainder is not described in further detail, the usage of Electricity by light duty vehicles is entirely attributed to Automobiles. ${ }^{2}$ Electricity usage by Pipeline reported is 240 trBTU (TEDB: Table 2.5, 2007) and 27.4 trBTU (TEDB: Table A.11, 2010). The data in Table A.11 is more detailed than the data in Table 2.5, therefore the Electricity usage by Pipeline in 2005 is reported as 27.4 trBTU.
} 


\section{Ethanol:}

Ethanol is consumed by vehicles either as E85 fuel ( $85 \%$ ethanol, 15\% gasoline) or as an oxygenated blending component (typically $\sim 10 \%$ ) of traditional gasoline. In this analysis, we have depicted the ethanol portion of E85 consumption as a direct flow from Ethanol to vehicles and we have depicted oxygenate consumption as a flow from Ethanol into the Gasoline fuel supply.

\section{Ethanol-> Gasoline}

Ethanol is used as a blending component in oxygenated gasoline by Automobiles and Light Trucks. The use of Ethanol in Gasoline is reported as 2.8 billion gasoline-equivalent gallons or 340 trBTUs in 2005 (TEDB: Table2.4, 2010).

Ethanol -> Automobiles

In 2005, 37.8 million gasoline-equivalent gallons of E85 were consumed by light duty vehicles (ATTF: Table C5, 2010), 85\% of which is Ethanol. This flow is split between Automobiles (33\%) and Light Trucks (67\%), based on the number of light duty vehicles in service in 2008 using E85 as a fuel (ATTF: Table V5, 2010). Therefore, the use of 10.7 million gasoline-equivalent gallons or 1.3 trBTUs of Ethanol is attributed to Automobiles.

\section{Ethanol -> Light Trucks}

In 2005, 37.8 million gasoline-equivalent gallons of E85 were consumed by light duty vehicles (ATTF: Table C5, 2010), 85\% of which is Ethanol. This flow is split between Light Trucks (67\%) and Automobiles (33\%), based on the number of light duty vehicles in service in 2008 using E85 as a fuel (ATTF: Table V5, 2010.). Therefore, 21.7 million gasoline-equivalent gallons or 2.7 trBTUs of Ethanol is attributed to Light Trucks.

\section{Ethanol -> Medium \& Heavy Trucks}

In 2005, 304 thousand gasoline-equivalent gallons of E85 were consumed by medium duty vehicles (ATTF: Table C5, 2010), 85\% of which is Ethanol. The usage of Ethanol by medium duty vehicles is wholly attributed to Medium \& Heavy Trucks. Therefore, 260 thousand gasoline-equivalent gallons or 0.032 trBTUs of Ethanol is used by Medium \& Heavy Trucks.

\section{Biodiesel:}

Specific data on the use of Biodiesel by vehicle class could not be found. As a whole, Biodiesel use is reported as 92 million gasoline-equivalent gallons in 2005 (TEDB: Table 2.3, 2010). In this analysis, we have assumed that the consumption of Biodiesel follows the same pattern as the consumption of Diesel \& Distillate Fuel Oil in Automobiles, Light Trucks, and Medium \& Heavy Trucks. ${ }^{3}$

\footnotetext{
${ }^{3}$ The use of Biodiesel is not attributed to any one class of transportation vehicle in the Transportation Energy Data Book (TEDB, 2010) or the Alternatives to Traditional Transportation Fuels report (ATTF, 2010), except for Transit Buses, for which Biodiesel is reported as first being used in 2006. Therefore, Biodiesel is assumed to be used by Automobiles, Light Trucks, and Medium \& Heavy Trucks in the same fraction as these vehicles use Diesel \& Distillate Fuel Oil.
} 


\section{Biodiesel -> Automobiles}

The usage of Biodiesel by Automobiles is estimated as 0.011 of the total, the same ratio of Diesel \& Distillate Fuel Oils used by Automobiles to the Diesel \& Distillate Fuel Oils used by Automobiles, Light Trucks, and Medium \& Heavy Trucks. Therefore the use of Biodiesel by Automobiles is estimated as 1.0 million gasoline-equivalent gallons or 0.12 trBTUs.

\section{Biodiesel -> Light Trucks}

The usage of Biodiesel by Light Trucks is estimated as 0.066 of the total, the ratio of Diesel \& Distillate Fuel Oil used by Light Trucks to that used by Automobiles, Light Trucks, and Medium \& Heavy Trucks. Therefore the use of Biodiesel by Light Trucks is estimated as 6.1 million gasoline-equivalent gallons or 0.76 trBTUs.

\section{Biodiesel -> Medium \& Heavy Trucks}

The usage of Biodiesel by Medium \& Heavy Trucks is estimated as 0.92 of the total, the ratio of Diesel \& Distillate Fuel Oil used by Medium \& Heavy Trucks to that used by Automobiles, Light Trucks, and Medium \& Heavy Trucks. Therefore the Biodiesel by Medium \& Heavy Trucks is estimated as 85 million gasoline-equivalent gallons or 11 trBTUs.

\section{Hydrogen:}

\section{Hydrogen -> Automobiles}

11 thousand gasoline-equivalent gallons of Hydrogen or 0.0014 trBTUs are reported as used in light duty vehicles (ATTF: Table C5, 2010). ${ }^{4}$ This flow of Hydrogen, 0.0014 trBTUs, is entirely attributed to Automobiles.

\section{Hydrogen -> Transit Buses}

14 thousand gasoline-equivalent gallons of Hydrogen or 0.0017 trBTUs are reported as consumed by heavy duty vehicles (ATTF: Table C5, 2010), which are assumed to be Transit Buses. ${ }^{5}$ Therefore, the flow from Hydrogen to Transit Buses is 0.0017 trBTUs.

CNG:

CNG -> Automobiles

In 2005, light duty vehicles consumed 29 million gasoline-equivalent gallon of CNG (ATTF: Table C5, 2010). Over $40 \%$ of the number of light duty vehicles in service in 2008 using $C N G$ as a fuel were Automobiles in 2008 (ATTF: Table V5, 2010). Assuming this percentage of vehicles holds true in 2005, the usage of $C N G$ by Automobiles is estimated as $40 \%$ of the total: 12 million gasoline-equivalent gallons or 1.4 trBTUs.

\footnotetext{
${ }^{4}$ Nearly $75 \%$ of the light duty vehicles in service in 2008 using Hydrogen as a fuel were Automobiles (ATTF: Table $\mathrm{V} 5,2010)$. As the remaining flow of energy ( 0.00035 trBTUs) is small, the entire 0.0014 trBTUs of Hydrogen usage is attributed to Automobiles.

${ }^{5}$ As reported by the National Renewable Energy Laboratory (NREL, 2011), Transit Buses are one of the best early transportation applications for fuel cell technology. All of the active projects reported by this source utilizing Hydrogen as a fuel source are Transit Buses.
} 
CNG -> Light Trucks

In 2005, light duty vehicles used 29 million gasoline-equivalent gallon of CNG (ATTF: Table C5, 2010). Nearly $60 \%$ of the number of light duty vehicles in service in 2008 using CNG as a fuel were light trucks, vans, or sport utility vehicles in 2008 (ATTF: Table V5, 2010), which are considered to be Light Trucks in this analysis. Assuming this percentage of vehicles holds true in 2005, the usage of CNG by Light Trucks is estimated as $60 \%$ of the total: 17 million gasoline-equivalent gallons or 2.2 trBTUs of CNG.

\section{CNG -> Medium \& Heavy Trucks}

In 2005, CNG use by medium duty vehicles is reported as 19 million gasoline-equivalent gallons or 2.4 trBTUs and use by heavy duty vehicles is reported as 120 million gasoline-equivalent gallons or 15 trBTUs (ATTF: Table C5, 2010). As described below, Transit Buses used 15 trBTUs of CNG in 2005. The CNG fuel used by medium and heavy duty vehicles not consumed by Transit Buses (2.1 trBTUs) is attributed to Medium \& Heavy Trucks.

CNG -> Transit Buses

Transit Buses used 120 million diesel-gallon equivalents of CNG in 2005 (TEDB: Table A.3, 2010). The CNG fuel use attributed to Transit Buses is equivalent to 15 trBTUs of energy.

\section{Methanol:}

Methanol -> Transit Buses

Transit Buses used 8.1 million gallons of methanol in 2005 (TEDB: Table A.3, 2010). This Methanol fuel use attributed to Transit Buses is equivalent to 0.52 trBTUs of energy.

$\underline{\text { LNG: }}$

LNG -> Light Trucks

LNG use by light duty vehicles is reported as 59 thousand gasoline-equivalent gallons in 2005 (ATTF: Table C5, 2010). ${ }^{6}$ Assuming the usage of $L N G$ is also dominated by pickup trucks in 2005 , the entire $L N G$ usage of 0.0074 trBTUs by light duty vehicles is attributed to Light Trucks.

LNG-> Medium \& Heavy Trucks

In 2005, LNG use by medium duty vehicles is reported as 190 thousand gasoline-equivalent gallons or 0.024 trBTUs and use by heavy duty vehicles is reported as 22 million gasoline-equivalent gallons or 2.8 trBTUs (ATTF: Table C5, 2010). As described below, Transit Buses used 1.7 trBTUs of LNG in 2005 (TEDB: Table A.3, 2010). The $L N G$ fuel use by medium and heavy duty vehicles not attributed to Transit Buses (1.1 trBTUs) is attributed to Medium \& Heavy Trucks.

\footnotetext{
${ }^{6}$ The entire amount of $L N G$ used by light duty vehicles in 2005 is attributed to Light Trucks in this analysis. As reported in the Alternatives to Traditional Transportation Fuels report, over 90\% of the LNG-fueled light duty vehicles are pickup trucks (ATTF: Table V5, 2010). Because the $L N G$ energy usage is relatively small (less than 0.01 trBTUs) and the vast majority is used by Light Trucks, the entire LNG fuel usage is attributed to Light Trucks.
} 
LNG-> Transit Buses

Transit Buses used 18 million gallons of $L N G$ in 2005 (TEDB: Table A.3, 2010). The LNG fuel use attributed to Transit Buses is calculated to be 1.7 trBTUs of energy.

$\underline{\text { LPG: }}$

LPG -> Light Trucks

Light Trucks used 470 million gallons of LPG in 2005 (TEDB: Table A.5, 2010). The LPG fuel use attributed to Light Trucks is calculated to be 43 trBTUs of energy.

LPG -> Medium \& Heavy Trucks

Medium \& Heavy Trucks used 190 million gallons of $L P G$ in 2005 (TEDB: Table A.6, 2010). The LPG fuel use attributed to Medium \& Heavy Trucks is calculated to be 17 trBTUs of energy.

LPG -> Transit Buses

Transit Buses used 2.0 million gallons of $L P G$ in 2005 (TEDB: Table A.3, 2010). The $L P G$ fuel use attributed to Transit Buses is calculated to be 0.18 trBTUs of energy.

\section{Gasoline:}

Gasoline -> Automobiles

Automobiles used 52 billion gallons of gasoline, 25 billion gallons of oxygenated gasoline, and 1.9 million gallons of gasoline blended into E85 fuel in 2005 (TEDB: Tables 2.3 and A.1, 2010 and ATTF: Table C5, 2010). The Gasoline fuel use attributed to Automobiles is calculated to contain 9,500 trBTUs of energy including the ethanol blended as an oxygenate.

Gasoline -> Motorcycles

Motorcycles used 19 million gallons of Gasoline (TEDB: Table A.2, 2010). The Gasoline fuel use attributed to Motorcycles is calculated to contain 24 trBTUs of energy.

Gasoline -> Light Trucks

Light Trucks used 37 billion gallons of gasoline, 19 billion gallons of oxygenated gasoline, and 3.8 million gallons of gasoline blended into E85 fuel in 2005 (TEDB: Tables 2.3 and A.5, 2010 and ATTF: Table C5, 2010). The Gasoline fuel use attributed to Light Trucks is calculated to contain 6,900 trBTUs of energy including ethanol blended as an oxygenate.

Gasoline -> Medium \& Heavy Trucks

Medium \& Heavy Trucks used 4.1 billion gallons of gasoline and 46 thousand gallons of gasoline blended into E85 fuel in 2005 (TEDB: Table A.6, 2010 and ATTF: Table C5, 2010). The Gasoline fuel use attributed to Medium \& Heavy Trucks is calculated to contain 510 trBTUs of energy.

Gasoline -> Transit Buses

Transit Buses used 1.0 million gallons of Gasoline in 2005 (TEDB: Table A.3, 2010). The Gasoline fuel use attributed to Transit Buses is calculated to contain 0.12 trBTUs of energy. 
Gasoline -> Intercity \& School Buses

Intercity \& School Buses used 53 million gallons of Gasoline in 2005 (TEDB: Table A.4, 2010). The

Gasoline fuel use attributed to Intercity \& School Buses is calculated to contain 6.6 trBTUs of energy.

Gasoline -> General Aviation

General Aviation used 320 million gallons of aviation gasoline in 2005 (TEDB: Table A.7, 2010). While the actual formulation of aviation gasoline is different from gasoline used in Automobiles and Light Trucks, the energy content of the fuel is similar. Because of this, Aviation Gasoline is included on this flowchart as Gasoline. The Gasoline fuel use attributed to General Aviation is calculated to contain 39 trBTUs of energy.

Gasoline -> Recreational Boating

Recreational Boating used 1.6 billion gallons of Gasoline in 2005 (TEDB: Table A.10, 2010). The Gasoline fuel use attributed to Recreational Boating is calculated to contain 200 trBTUs of energy.

Jet Fuel:

Jet Fuel -> General Aviation

General Aviation used 1.5 billion gallons of Jet Fuel in 2005 (TEDB: Table A.7, 2010). The Jet Fuel use attributed to General Aviation is calculated to contain 200 trBTUs of energy.

Jet Fuel -> Commercial Aircraft

Commercial Aircraft include commercial passenger carriers and air freight carriers, and the fuel use described in this flowchart encompasses domestic and international departures. Commercial Aircraft used 19 billion gallons of Jet Fuel in 2005 (TEDB: Table A.8, 2010). The Jet Fuel use attributed to Commercial Aircraft is calculated to contain 2,600 trBTUs of energy.

\section{Diesel \& Distillate Fuel Oil:}

Diesel \& Distillate Fuel Oil -> Automobiles

Automobiles used 390 million gallons of Diesel Fuel in 2005 (TEDB: Table A.1, 2010). The Diesel \&

Distillate Fuel Oil fuel use attributed to Automobiles is calculated to contain 54 trBTUs of energy.

Diesel \& Distillate Fuel Oil -> Light Trucks

Light Trucks used 2.4 billion gallons of Diesel Fuel in 2005 (TEDB: Table A.5, 2010). The Diesel \& Distillate Fuel Oil fuel use attributed to Light Trucks is calculated to contain 330 trBTUs of energy.

Diesel \& Distillate Fuel Oil -> Medium \& Heavy Trucks

Medium \& Heavy Trucks used 33 billion gallons of Diesel Fuel in 2005 (TEDB: Table A.6, 2010). The Diesel \& Distillate Fuel Oil fuel use attributed to Medium \& Heavy Trucks is calculated to contain 4,600 trBTUs of energy. 
Diesel \& Distillate Fuel Oil -> Transit Buses

Transit Buses used 530 million gallons of Diesel Fuel in 2005 (TEDB: Table A.3, 2010). The Diesel \&

Distillate Fuel Oil fuel use attributed to Transit Buses is calculated to contain 74 trBTUs of energy.

Diesel \& Distillate Fuel Oil -> Intercity \& School Buses

Intercity \& School Buses used 690 million gallons of Diesel Fuel in 2005 (TEDB: Table A.4, 2010). The

Diesel \& Distillate Fuel Oil fuel use attributed to Intercity \& School Buses is calculated to contain 96 trBTUs of energy.

Diesel \& Distillate Fuel Oil -> Passenger Rail

Passenger Rail used 140 million gallons of Diesel Fuel in 2005 (TEDB: Tables A.13-A.15, 2010). The Diesel \& Distillate Fuel Oil fuel use attributed to Passenger Rail is calculated to contain 20 trBTUs of energy.

Diesel \& Distillate Fuel Oil -> Freight Rail

Freight Rail used 4.1 billion gallons of Diesel Fuel in 2005 (TEDB: Table A.12, 2010). The Diesel \&

Distillate Fuel Oil fuel use attributed to Freight Rail is calculated to contain 570 trBTUs of energy.

Diesel \& Distillate Fuel Oil -> Recreational Boating

Recreational Boating used 300 million gallons of Distillate Fuel Oil in 2005 (TEDB: Table A.10, 2010). The

Diesel \& Distillate Fuel Oil fuel use attributed to Recreational Boating is calculated to contain 42 trBTUs

of energy.

Diesel \& Distillate Fuel Oil -> Commercial Shipping

Commercial Shipping used 2.1 billion gallons of Distillate Fuel Oil in 2005 (TEDB: Table A.9, 2010). The Diesel \& Distillate Fuel Oil fuel use attributed to Commercial Shipping is calculated to contain 290 trBTUs of energy.

Residual Fuel Oil:

Residual Fuel Oil -> Commercial Shipping

Commercial Shipping used 5.5 billion gallons of Residual Fuel Oil in 2005 during international as well as domestic departures (TEDB: Table A.9, 2010). The Residual Fuel Oil fuel use attributed to Commercial Shipping is calculated to contain 830 trBTUs of energy.

\section{Refined Fuels Production:}

The fuels described above are manufactured from energy resources present in the environment. In some cases (e.g. petroleum refining) entire industrial sectors exist primarily to support the production of transportation fuels. In other cases (e.g. electricity production) transportation consumes a small fraction of the sector's output. In all cases, the quantities depicted here pertain only to the portion of fuel consumed by the transportation sector.

All transportation fuels depend on a chain of energy transformations beginning with resource extraction and ending with final fuel production. This analysis depicts that final step, and excludes all steps 
upstream of manufacture. This choice in system boundaries creates some "overlap" with other energy flow chart analyses.

\section{Biomass Refining}

The biofuels sector is comprised of ethanol manufacturing and biodiesel manufacturing.

Biomass Refining -> Ethanol

The amount of Ethanol consumed by vehicles in 2005 is reported as 38 million gasoline-equivalent gallons of E85 of which $85 \%$ is Ethanol and 2.8 billion gasoline equivalent-gallons of Ethanol used in oxygenated gasoline in 2005 (TEDB Table 2.3, 2010). From these quantities, the energy from Biomass Refining transformed into Ethanol is calculated to be 350 trBTUs in 2005.

\section{Biomass Refining $->$ Biodiesel}

The amount of Biodiesel used as an alternative fuel in 2005 is reported as 92 million gasoline-equivalent gallons (TEDB Table 2.3, 2010). With 125,000 BTUs per gasoline-equivalent gallon, the energy from Biomass Refining transformed into Biodiesel is calculated to be 11 trBTUs in 2005.

\section{Natural Gas Refining}

Transportation fuels derived from natural gas include Compressed Natural Gas (CNG), Liquefied Natural Gas (LNG), methanol and hydrogen. Natural gas is also consumed directly at pipeline compression stations - after it has undergone processing but before it is packaged for consumption by other parts of the transportation sector.

\section{Natural Gas Refining -> Hydrogen}

The amount of Hydrogen used as an alternative fuel in 2005 is estimated as 25 thousand gasolineequivalent gallons (TEDB Table 2.3, 2010). Most hydrogen is produced via the steam reforming of natural gas. The energy from Natural Gas Refining transformed into Hydrogen is calculated to be 0.0031 trBTUs.

Natural Gas Refining -> CNG

The amount of CNG used as an alternative fuel in 2005 is estimated as 170 million gasoline-equivalent gallons (TEDB Table 2.3, 2010). From this, the energy from Natural Gas Refining transformed into CNG is calculated to be 21 trBTUs in 2005.

\section{Natural Gas Refining -> Methanol}

The amount of Methanol used as an alternative fuel in 2005 is reported as 8.1 million gallons (TEDB: Table A.3, 2010). The energy from Natural Gas Refining transformed into Methanol is calculated to be 0.52 trBTUs in 2005. 
Natural Gas Refining $\rightarrow$ LNG

The amount of $L N G$ used as an alternative fuel in 2005 is reported as 22 million gasoline-equivalent gallons (TEDB: Table 2.3, 2010). The energy from Natural Gas Refining transformed into $L N G$ is calculated to be 2.8 trBTUs.

Natural Gas Refining -> Pipeline

Fuels are moved throughout the United States using pipelines. In 2005, the transportation of these fuels used 580 billion cubic feet of Natural Gas ( 600 trBTUs) and 2.6 billion kilowatt hours of electricity (24 trBTUs). The fuel from Natural Gas Refining attributed to transporting fuels by Pipeline is calculated to be 600 trBTUs of energy.

\section{Petroleum Refining}

Petroleum Refining -> LPG

The amount of $L P G$ used in the transportation sector in 2005 is reported as 660 million gallons (TEDB: Tables A.3, A.5, and A.6, 2010). Therefore, the energy from Petroleum Refining transformed into $L P G$ is calculated to be 60 tBTUs.

\section{Petroleum Refining -> Gasoline}

The amount of Gasoline used in 2005 is reported as 95 billion gallons: 93 billion gallons as gasoline, 5.7 million gallons as the gasoline portion of $\mathrm{E} 85$, and 44 billion gallons as oxygenated gasoline- also referred to as gasohol (TEDB: Tables 2.3 and Appendix A, 2010). Therefore, the energy from Petroleum Refining transformed into Gasoline is calculated to be 17,000 trBTUs including the gasoline portion of E85 (TEDB, 2008).

\section{Petroleum Refining -> Jet Fuel}

The amount of Jet Fuel used in 2005 is reported as 21 billion gallons (TEDB: Tables A.7 and A.8, 2010). The energy from Petroleum Refining transformed into Jet Fuel is calculated to be 2,800 trBTUs in 2005 (TEDB, 2010).

Petroleum Refining $\rightarrow>$ Diesel \& Distillate Fuel Oils

The amount of Diesel \& Distillate Fuel Oils used in 2005 is reported as 44 billion gallons (TEDB: Tables A.1, A.3-A.6, A.9-A.10, A.12-A.13, and A.15, 2010). The energy from Petroleum Refining transformed into Diesel \& Distillate Fuel Oils is calculated to be 6,000 trBTUs in 2005 (TEDB, 2010).

\section{Petroleum Refining ->Residual Fuel Oil}

The amount of Residual Fuel Oil used in 2005 is reported as 5.5 billion gallons (TEDB: Tables A.9, 2010). The energy from Petroleum Refining transformed into Residual Fuel Oil is calculated to be 830 trBTUs in 2005 (TEDB, 2010). 


\section{Energy Disposition:}

\section{Energy Services}

This value is estimated as the sum of all propulsive and other useful work from transportation activities including Automobiles, Motorcycles, Light Trucks, Medium \& Heavy Trucks, Transit Buses, Intercity \& School Buses, Pipeline, General Aviation, Commercial Aircraft, Passenger Rail, Freight Rail, Recreational Boating, and Commercial Shipping.

\section{Rejected Energy}

Rejected energy represents the energy consumed by the transportation sector, which is not converted to propulsive or other useful work. This is the sum of all Rejected Energy from all transportation activities including Automobiles, Motorcycles, Light Trucks, Medium \& Heavy Trucks, Transit Buses, Intercity \& School Buses, Pipeline, General Aviation, Commercial Aircraft, Passenger Rail, Freight Rail, Recreational Boating, and Commercial Shipping.

\section{Energy Services}

Energy services in the transportation sector can be approximated by the sum of propulsive work (the mechanical work required to overcome aerodynamic drag, rolling resistance and vehicle inertia) and other useful work (minimum work required to run auxiliary and accessory loads in vehicles). In this analysis, we have assumed that all auxiliary and accessory services are delivered at $50 \%$ efficiency (i.e. $50 \%$ of energy delivered to auxiliary and accessory loads is a service, while the remainder is rejected).

\section{Automobiles -> Energy Services}

Energy use by Automobiles for combined city and highway driving has been estimated using the following percentages: 70 - 72\% to engine losses, 3\% to standby or idling, 5 - $6 \%$ to accessories, 8 - 10\% to aerodynamic drag, 5 - $6 \%$ to rolling resistance, 5 - $6 \%$ to drivetrain losses, and $4-5 \%$ to braking (Fuel Economy, 2011). Defining useful energy to include the energy necessary to overcome aerodynamic drag, rolling resistance, braking, and half of the energy used by accessories, using the average percentages of the provided ranges, $22 \%$ of the total energy is attributed to Energy Services. Therefore, the flow from Automobiles to Energy Services is calculated as 2,100 trBTUs.

\section{Motorcycles -> Energy Services}

The energy efficiency of Motorcycles powered by gasoline is reported to be $15 \%$ (Chiu, 1999). Therefore, the flow from Motorcycles to Energy Services is calculated as $15 \%$ of the energy from Motorcycles, or 3.5 trBTUs.

\section{Light Trucks -> Energy Services}

The energy efficiency of Light Trucks is estimated by assuming the percent of useful work accomplished by Light Trucks is equivalent to that of Automobiles. Therefore, the total energy efficiency for Light Trucks is $22 \%$ and the flow from Light Trucks to Energy Services is calculated as $22 \%$ of the energy from Light Trucks, or 1,600 trBTUs. 
Medium \&Heavy Trucks -> Energy Services

Energy use by Medium \& Heavy Trucks is estimated using the following percentages: $60 \%$ to engine losses, $21 \%$ to aerodynamic drag, $13 \%$ to rolling resistance, $4 \%$ to auxiliary losses, and $2 \%$ to drivetrain (US CCTP, 2003). Defining useful energy services as the energy needed to overcome the aerodynamic drag, rolling resistance, half the auxiliary losses, and drivetrain, the percentage of useful energy for Medium \& Heavy Trucks is 38\%. Therefore, the flow from Medium \& Heavy Trucks to Energy Services is calculated to be 1,900 trBTUs.

\section{Transit Buses -> Energy Services}

The energy use by different functions in Transit Buses has been analyzed as a function of speed ranging from 20 - 50 miles per hour ( $\mathrm{mph}$ ) (Delorme, 2010). For this analysis, the energy usage by Transit Buses is calculated for a speed of $20 \mathrm{mph}$, assumed to be representative of average operating conditions. At a speed of $20 \mathrm{mph}, 61 \%$ of the energy is consumed by engine losses, $20.5 \%$ by accessories, $1.8 \%$ by transmission, $0.1 \%$ by axles, $14.4 \%$ by rolling resistance, and $2.2 \%$ by aerodynamic drag. The energy efficiency of Transit Buses is estimated by summing the contributions from rolling resistance, aerodynamic drag, and half of the accessories for a total of $27 \%$. Therefore, the flow from Transit Buses to Energy Services is calculated to be 25 trBTUs.

Intercity \& School Buses -> Energy Services

For this analysis, the energy efficiency for Intercity \& School Buses is estimated by using the energy distribution calculated for Transit Buses at a speed of $20 \mathrm{mph}$ for School Buses and $50 \mathrm{mph}$ for Intercity Buses (Delorme, 2010). Similar to Transit Buses, the Energy Services for School Buses traveling at an average of $20 \mathrm{mph}$ is estimated to be $27 \%$. The total energy used by School Buses is $73 \mathrm{trBTUs}$, therefore the flow from School Buses to Energy Services is calculated to be 20 trBTUs.

At a speed of $50 \mathrm{mph}, 59 \%$ of the energy in Intercity Buses is consumed by engine losses, $8 \%$ by accessories, $1.1 \%$ by transmission, $1.0 \%$ by axles, $16 \%$ by rolling resistance, and $15 \%$ by aerodynamic drag. The energy efficiency of Intercity Buses is estimated by summing the contributions from rolling resistance, aerodynamic drag, and half of the energy used by accessories for a total of $35 \%$. The total energy used by Intercity Buses is 30 trBTUs, therefore the flow from Intercity Buses to Energy Services is calculated as 10 trBTUs.

The total flow from Intercity \& School Buses to Energy Services is the sum of these two flows for a weighted average of $29 \%$ energy efficiency, or 30 trBTUs.

\section{Pipeline -> Energy Services}

The energy service provided by the Pipeline sector is equal to the work done overcoming fluid friction within the pipelines. The energy efficiency in Pipeline is estimated to be $30 \%$, about the efficiency of a compressor powered by a natural gas engine (Leslie, 2009). Therefore, the flow from Pipeline to Energy Services is calculated as $30 \%$ of the energy from Pipeline, or 190 trBTUs. 


\section{General Aviation -> Energy Services}

The most efficient aircraft have a thermal efficiency of $55-60 \%$ and propulsive efficiency of $65-70 \%$ (Schafer, 2009). A separate source finds the thermal efficiency of small aircraft to be $30 \%$ (Paulus, 2003). Because the fleet of aircraft used in General Aviation is assumed to have lower efficiencies than the most efficient aircraft, the overall energy efficiency is estimated using $40 \%$ thermal efficiency (between the thermal efficiencies of the two sources) and $60 \%$ propulsive efficiency or $40 \% \times 60 \%$, for an overall efficiency of $24 \%$. Therefore, the flow from General Aviation to Energy Services is calculated to be 58 trBTUs.

\section{Commercial Aircraft -> Energy Services}

The most efficient aircraft have a thermal efficiency of $55-60 \%$ and propulsive efficiency of $65-70 \%$ (Schafer, 2009). To take into account less efficient aircraft, the efficiencies for Commercial Aircraft are estimated using the percentages at the low end of the ranges or $55 \% \times 65 \%$, for an overall efficiency of $36 \%$. Therefore, the flow from Commercial Aircraft to Energy Services is calculated to be 930 trBTUs.

\section{Passenger Rail -> Energy Services}

The energy efficiency for Passenger Rail varies significantly for trains fueled by diesel fuel or electricity; both fuels are used in significant amounts. Passenger Rail electric engines used 66 trBTUs of energy as electricity in 2005, which are 65\% efficient (Lindgreen, 2005). Passenger Rail diesel engines used 20 trBTUs of energy as diesel fuel in 2005, the efficiency of which are assumed to be equivalent to Freight Rail at 30\% (Lindgreen, 2005). The overall energy efficiency in Passenger Rail is calculated to be $57 \%$ from a weighted average. Therefore, the flow from Passenger Rail to Energy Services is calculated to be 49 trBTUs.

\section{Freight Rail -> Energy Services}

The energy efficiency of Freight Rail using diesel engines is estimated to be $30 \%$ (Lindgreen, 2005). Therefore, the flow from Freight Rail to Energy Services is calculated to be 170 trBTUs.

\section{Recreational Boating -> Energy Services}

The propulsive coefficient of marine pleasure craft is reported as $66 \%$ and the thermal efficiency of marine gasoline engines is reported to be between 25 - 35\% (AEA, 2008). The energy efficiency of Recreational Boating is estimated to be $66 \% \times 30 \%$, for an overall efficiency of $20 \%$. Therefore, the flow from Recreational Boating to Energy Services is calculated to be 49 trBTUs.

\section{Commercial Shipping -> Energy Services}

The propulsive coefficient (ratio of the effective power to the power measured at the thrust block) of merchant ships is reported as ranging between 60 - 70\% (Barrass, 2004). The thermal efficiency of marine diesel engines is reported to be $45 \%$ (Rowen, 2008). Therefore, the energy efficiency of Commercial Shipping is estimated to be $65 \%$ x $45 \%$, for an overall efficiency of $29 \%$. Therefore, the flow from Commercial Shipping to Energy Services is calculated to be 330 trBTUs. 


\section{Rejected Energy}

Energy rejected from the transportation sector includes all of the energy rejected (usually as waste heat or drivetrain losses) from the operation of vehicles and their accessories. This analysis also includes the energy rejected as waste heat or materials from the final manufacturing step in the fuels production supply chains.

\section{Automobiles -> Rejected Energy}

As described above, Automobiles are estimated to have an efficiency of $22 \%$. Therefore, the flow from Automobiles to Rejected Energy is calculated as 78\% of the energy from Automobiles, or 7,500 trBTUs.

Motorcycles ->Rejected Energy

As described above, Motorcycles are estimated to have an efficiency of $15 \%$. Therefore, the flow from Motorcycles to Rejected Energy is calculated as 85\% of the energy from Motorcycles, or 20 trBTUs.

Light Trucks -> Rejected Energy

As described above, Light Trucks are estimated to have an efficiency of $22 \%$. Therefore, the flow from Light Trucks to Rejected Energy is calculated as 78\% of the energy from Light Trucks, or 5,700 trBTUs.

\section{Medium \& Heavy Trucks -> Rejected Energy}

As described above, Medium \& Heavy Trucks are estimated to have an efficiency of $38 \%$. Therefore, the energy flow from Medium \& Heavy Trucks to Rejected Energy is calculated as $62 \%$ of the energy from Medium \& Heavy Trucks, or 3,200 trBTUs.

\section{Transit Buses -> Rejected Energy}

As described above, Transit Buses are estimated to have an efficiency of $27 \%$. Therefore, the energy flow from Transit Buses to Rejected Energy is calculated as 73\% of the energy from Transit Buses, or 67 trBTUs.

Intercity \& School Buses -> Rejected Energy

As described above, Intercity \& School Buses are estimated to have a weighted energy efficiency of $29 \%$. Therefore, the energy flow from Intercity \& School Buses to Rejected Energy is calculated as $71 \%$ of the energy from Intercity \& School Buses, or 73 trBTUs.

Pipeline -> Rejected Energy

As described above, Pipeline is estimated to have an efficiency of $30 \%$. Therefore, the flow from Pipeline to Rejected Energy is calculated as $70 \%$ of the energy from Pipeline, or 440 trBTUs.

\section{General Aviation -> Rejected Energy}

As described above, General Aviation is estimated to have an efficiency of $24 \%$. Therefore, the flow from General Aviation to Rejected Energy is calculated as $76 \%$ of the energy from General Aviation, or 180 trBTUs. 
Commercial Aircraft -> Rejected Energy

As described above, Commercial Aircraft are estimated to have an energy efficiency of $36 \%$. Therefore, the flow from Commercial Aircraft to Rejected Energy is calculated as $64 \%$ of the energy from Commercial Aircraft, or 1,700 trBTUs.

Passenger Rail -> Rejected Energy

As described above, Passenger Rail is estimated to have a weighted energy efficiency of $57 \%$. Therefore, the flow from Passenger Rail to Rejected Energy is calculated as $43 \%$ of the energy from Passenger Rail, or 37 trBTUs.

Freight Rail -> Rejected Energy

As described above, Freight Rail is estimated to have an energy efficiency of $30 \%$. Therefore, the flow from Freight Rail to Rejected Energy is $70 \%$ of the energy from Freight Rail, or 400 trBTUs.

Recreational Boating $\rightarrow$ Rejected Energy

As described above, Recreational Boating is estimated to have an energy efficiency of $20 \%$. The flow from Recreational Boating to Rejected Energy is calculated as $80 \%$ of the energy from Recreational Boating, or 200 trBTUs.

Commercial Shipping -> Rejected Energy

As described above, Commercial Shipping is estimated to have an energy efficiency of $29 \%$. The flow from Commercial Shipping to Rejected Energy is calculated as $71 \%$ of the energy from Commercial Shipping, or 800 trBTUs.

Electricity Production -> Rejected Energy

Electricity Production efficiency ranges from 33-52\% and electricity delivery losses are estimated at $8 \%$ of generated electricity. From these values, the total efficiency of Electricity Production is estimated to be $32 \%$. Therefore, as 94 trBTUs of electricity are used by the transportation sector, the total energy required to produce this amount of electricity is $94 \mathrm{trBTUs} / 32 \%$, or $290 \mathrm{trBTUs}$. Therefore, the energy flow from Electricity to Rejected Energy is calculated as $290-94$ trBTUs, or 200 trBTUs.

Biomass Refining $\rightarrow$ Rejected Energy

The processing of Ethanol by dry mill from corn uses 202,000 BTUs per gallon: 153,000 BTUs present in corn and 49,000 BTUs used to convert the corn into Ethanol (PennState, 2009; Rowlett, 2001; Shapouri, 2002). This process produces one gallon of Ethanol containing 76,000 BTUs using a dry mill (Shapouri, 2002; TEDB, 2010). Therefore, the processing of ethanol is estimated to be $38 \%$ efficient.

In comparison, 390,000 BTUs of energy are consumed during the processing of one gallon of Biodiesel from soybeans: 350,000 BTUs present in soybeans (Mourad, 2011; Conley, 2006), 23,200 BTUs in 
soybean crushing, and 18,800 BTUs in Biodiesel conversion (Pradhan, 2009). ${ }^{7}$ The product, 1 gallon of Biodiesel, contains 120,000 BTUs (TEDB, 2010). Biodiesel processing is estimated to be $31 \%$ efficient.

Given the useful energy of 350 trBTUs in ethanol and 11 trBTUs in biodiesel, the Rejected Energy from Biomass Refining is calculated as (350 / 38\% - 350) or 571 trBTUs from ethanol conversion and ( 11 / 31\% - 11) or 24 trBTUs from biodiesel conversion. The total flow from Biomass Refining to Rejected Energy is the sum of these two flows, 590 trBTUs.

Natural Gas Refining -> Rejected Energy

In 2007, the processing of natural gas in North America was estimated as $97.2 \%$ efficient (CEC, 2007). Natural gas liquefaction and compression incur additional losses, as do the production of hydrogen or methanol from natural gas. However, because $96 \%$ of natural gas use in transportation consumes gas directly from the pipelines, those processing losses are negligible. Therefore, the energy flow from Natural Gas Refining to Rejected Energy is calculated as $2.8 \%$ of the total energy, 18 trBTUs.

Petroleum Refining -> Rejected Energy

Using a top-down approach, the efficiency of Petroleum Refining is calculated using the energy and material inputs and outputs. The inputs in Petroleum Refining for the transportation sector are estimated to be 27,000 trBTUs in 2005: 25,000 trBTUs of crude oil (Refinery Receipts, 2010), 100 trBTUs of electricity, 600 trBTUs of natural gas, 1,200 trBTUs of still gas, 450 trBTUs of petroleum coke, and 50 trBTUs of steam (U.S. EIA, 2010). The products have energy contents of 25,000 trBTUs. From this calculation, the Petroleum Refining process is estimated to be $91 \%$ efficient. Using the bottom-up approach to calculating energy present in petroleum products used in the transportation sector in 2005, the total energy flow to products is 27,000 trBTUs. Therefore, the energy flow from Petroleum Refining to Rejected Energy is calculated from 27,000 / $91.5 \%$ - 27,000, or 2,500 trBTUs.

\section{Fuel production Sector:}

Electricity Production:

Electricity Production represents the sum of electricity used by Automobiles, Medium \& Heavy Trucks, Transit Buses, Pipeline, and Passenger Rail and the energy rejected in producing this electricity. The total energy flow through Electricity Production in 2005 is 290 trBTUs.

\section{Biomass Refining:}

Biomass Refining represents the energy delivered to Automobiles, Light Trucks, Medium \& Heavy Trucks, and Transit Buses via ethanol fuel (E85), biodiesel and ethanol blended into gasoline. It also includes the energy rejected in the manufacture of those fuels. The total energy flow through Biomass Refining in 2005 is therefore 950 trBTUs.

\footnotetext{
${ }^{7}$ These calculations do not remove the energy associated with making co-products including soybean meal and crude glycerin. Removing the energy associated with making these products would greatly increase the efficiency of this Biomass Refining of Biodiesel.
} 


\section{Natural Gas Refining:}

Natural Gas Refining represents the fuel and energy used to produce Hydrogen, Compressed Natural Gas (CNG), Methanol, Liquefied Natural Gas (LNG), along with the natural gas used in Pipeline activities in the transportation sector and the energy rejected in producing these products. In 2005, 23 billion cubic feet of natural gas ( 24 trBTUs) were used to power vehicles, while 580 billion cubic feet (600 trBTUs) were used to power compression stations in the natural gas transmission and distribution systems (NGCEU, 2011), and 18 trBTUs were rejected, for a total of 640 trBTUs.

Petroleum Refining:

Petroleum Refining represents the fuel and energy used to produce Liquefied Petroleum Gas (LPG), Gasoline, Jet Fuel, Diesel \& Distillate Fuel Oil, and Residual Fuel Oil for the transportation sector. It also includes the 2,500 trBTUs rejected in the manufacturing of these fuels. The energy flow through Petroleum Refining in 2005 is therefore 29,000 trBTUs.

\section{Conclusion}

The flow chart described in this report is a compact depiction of the national energy use in the transportation sector in 2005. This diagram is available at: http://flowcharts.IInl.gov 


\section{References}

AEA Energy \& Environment. Greenhouse gas emissions from shipping. Final Report. AEA/ED43808(4), 2008. Available at: http://hmccc.s3.amazonaws.com/pdfs/AEA\%20shipping\%20report\%20for\%20 the\%20CCC.pdf (AEA, 2008).

Barrass, C.B. Ship Design and Performance for Masters and Mates. Elsevier Butterworth-Heinemann, MA: 2004. ISBN 075066000 7. Available at: http://www.scribd.com/doc/55059019/Ship-Design-andPerformance-for-Masters-and-Mates\#archive. (Barrass, 2004)

California Energy Commission. Full Fuel Cycle Assessment: Well to Tank Energy Inputs, Emissions, and Water Impacts. February, 2007. Available at: http://www.energy.ca.gov/2007publications/CEC-6002007-002/CEC-600-2007-002-D.PDF (CEC, 2007).

College of Agricultural Sciences. Coping with High Energy Prices: Heat energy content of shelled corn. Pennsylvania State University, 2009. Available at: http://energy.cas.psu.edu/energycontent.html (PennState, 2009)

Conley, S.P. and B. Tao. "What is Biodiesel?" Purdue University, 2006. Available at: http://www.ces.purdue.edu/extmedia/ID/ID-337.pdf (Conley, 2006)

Chiu, Y.C. and G. H. Tzeng. "The market acceptance of electric motorcycles in Taiwan experience through a stated preference analysis." Transportation Research Part D: Transport and Environment: 4(2), p127146, 1999. Available at: http://www.sciencedirect.com/science/article/pii/S1361920999000012 (Chiu, 1999)

Delorme, A. et al. "Fuel consumption potential of medium- and heavy-duty applications." The $25^{\text {th }}$ World Battery, Hybrid, and Fuel Cell Electric Vehicle Symposium \& Exhibition. Shenzhen, China, Nov. 5-9, 2010. Available at: http://www.autonomie.net/docs/6\%20-\%20Papers/Heavy\%20duty/fuel_consumption_ potential.pdf (Delorme, 2010)

Environmental and Energy Study Institute. Energy Efficiency Fact Sheet: Automotive Efficiency. 2006. Available at: http://files.eesi.org/auto_efficiency_0506.pdf (EESI, 2006)

Lawrence Livermore National Laboratory, Energy Flow Charts. 2011. Available at: http://flowcharts.IInl.gov (Livermore, 2011)

Leslie, N.P. et al. "Recovered energy generation using an Organic Rankine cycle system." ASHRAE Transactions: 115(1), 2009. Available at: http://info.ornl.gov/sites/publications/files/Pub10841.pdf (Leslie, 2009)

Lindgreen, E. and S.C. Sorenson. Simulation of energy consumption and emissions from rail traffic. Report No. MEK-ET-2005-04, 2005. Available at: http://www.inrets.fr/ur/Ite/publiautresactions/fichesresultats/ficheartemis/non_road4/Artemis_del7a_rail.pdf (Lindgreen, 2005) 
Mourad, A.L. and A. Walter. "The energy balance of soybean biodiesel in Brazil: a case study." Biofuels, Bioproducts and Biorefining: 5(2), 185-197, 2011. Available at:

http://onlinelibrary.wiley.com/doi/10.1002/bbb.278/full (Mourad, 2011)

National Renewable Energy Laboratory. Hydrogen \& Fuel Cells Research: Hydrogen Fuel Cell Bus Evaluations, 2011. Available at: http://www.nrel.gov/hydrogen/proj_fc_bus_eval.html (NREL, 2011).

Oak Ridge National Laboratory. Transportation Energy Data Book: Edition 27, 2008. Available at: http://www.cleanenergycouncil.org/files/Edition27_Full_Doc.pdf (TEDB, 2008)

Oak Ridge National Laboratory. Transportation Energy Data Book: Edition 29, 2010. Available at: http://info.ornl.gov/sites/publications/files/Pub24318.pdf (TEDB, 2010).

Parajuli, A. et al. Freight modal energy efficiency: A comparison model. In Conference of Australian Institutes of Transport Research. December, 2003, University of South Australia, Adelaide. Available at: http://eprints.qut.edu.au/307/1/CAITR_\%28Freight_Energy_Use\%29.pdf (Parajuli, 2003).

Paulus, D.M. and Gaggioli, R. A. "The Exergy of Lift and Aircraft Exergy Flow Diagrams." Int. J. Thermodynamics: 6 (4), 149-156, 2003.

Pradhan, A. et al. Energy Life-Cycle Assessment of Soybean Biodiesel. U. S. Department of Agriculture: Agricultural Economic Report \# 845, September 2009. Available at:

http://www.usda.gov/oce/reports/energy/ELCAofSoybeanBiodiesel91409.pdf (Pradhan, 2009).

Rowen, A.L. "Marine engine," in AccessScience, McGraw-Hill Companies, 2008, Available at: http://www.accessscience.com. (Rowen, 2008).

Rowlett, R. "U.S. Commercial Bushel Sizes." University of North Carolina, 2001. Available at: http://www.unc.edu/ rowlett/units/scales/bushels.html (Rowlett, 2001)

Shapouri, H. et al. The Energy Balance of Corn Ethanol: An Update. July 2002. Available at: http://www.transportation.anl.gov/pdfs/AF/265.pdf (Shapouri, 2002).

U. S. Climate Change Technology Program: Technology Options for the Near and Long Term. November 2003. Available at: http://www.ewp.rpi.edu/hartford/ stephc/EP/Research/ Articles\%20\%26\%20Reports/CCTP_TechOptions_Paper.pdf. (US CCTP, 2003).

U.S. Department of Energy: Energy Efficiency \& Renewable Energy. Fuel Economy: Where the Energy Goes. October 2011. Available at: http://www.fueleconomy.gov/feg/atv.shtml. (Fuel Economy, 2011)

U.S. Energy Information Administration. Natural Gas Consumption by End Use. April, 2011. Available at: http://www.eia.doe.gov/dnav/ng/ng_cons_sum_dcu_nus_a.htm. (NGCEU, 2011). 
U.S. Energy Information Administration. Natural Gas Plant Processing. April 2011, Available at:

http://www.eia.doe.gov/dnav/ng/ng_prod_pp_dcu_nus_a.htm. (NGPP, 2011).

U.S. Energy Information Administration. Petroleum \& Other Liquids: Fuel Consumed at Refineries. June, 2010. Available at: http://www.eia.doe.gov/dnav/pet/pet_pnp_capfuel_dcu_nus_a.htm (U.S. EIA, 2010)

U.S. Energy Information Administration. Refinery Receipts of Crude Oil by Method of Transportation. June, 2010. Available at: http://www.eia.doe.gov/dnav/pet/pet_pnp_caprec_dcu_nus_a.htm (Refinery Receipts, 2010).

U.S. Energy Information Administration. Alternatives to Traditional Transportation Fuels: 2008. April, 2010. Available at: http://www.eia.gov/cneaf/alternate/page/atftables/afv-atf2008.pdf. (ATTF, 2010).

\section{Appendix}

Conversions used (TEDB, 2010):

\begin{tabular}{|c|c|c|}
\hline Gasoline-equivalent & 125,000 & BTUs/gasoline equivalent gallon \\
\hline Diesel-equivalent & 138,700 & BTUs/diesel-equivalent gallon \\
\hline Ethanol & 75,700 & BTUs/gallon of ethanol \\
\hline Biodiesel & 117,100 & BTUs/gallon of biodiesel \\
\hline Methanol & 64,600 & BTUs/gallon of methanol \\
\hline Natural Gas & 1,031 & BTUs/cubic foot of natural gas \\
\hline LNG & 90,800 & BTUs/gallon of LNG \\
\hline LPG & 91,300 & BTUs/gallon of LPG \\
\hline Gasoline & 125,000 & BTUs/gallon of gasoline \\
\hline Gasohol & 120,900 & BTUs/gallon of gasohol \\
\hline Aviation Gasoline & 120,200 & BTUs/gallon of aviation gasoline \\
\hline Jet Fuel & 135,000 & BTUs/gallon of jet fuel \\
\hline Diesel Fuel & 138,700 & BTUs/gallon of diesel fuel \\
\hline Distillate Fuel Oil & 138,700 & BTUs/gallon of distillate fuel oil \\
\hline Residual Fuel Oil & 149,700 & BTUs/gallon of residual fuel oil \\
\hline Electricity & 10,339 & BTUs/kW-hr \\
\hline
\end{tabular}

Glossary

Fuels:

Ethanol:

Ethanol is refined from Biomass. This fuel represents the Ethanol in E85 used by Automobiles, Light Trucks, and Medium \& Heavy Trucks and Ethanol used as a blending component in Gasoline.

Biodiesel:

Biodiesel is produced from Biomass Refining and is used by Automobiles, Light Trucks, and Transit Buses. 
Hydrogen:

In 2005, Hydrogen was produced by steam-reforming of natural gas. Hydrogen is used to fuel Automobiles and Transit Buses.

Compressed Natural Gas (CNG):

CNG is refined and compressed from Natural Gas and is used by Automobiles, Light Trucks, Medium \& Heavy Trucks, and Transit Buses.

Methanol:

Methanol is refined from Natural Gas and is used by Transit Buses.

Liquefied Natural Gas (LNG):

LNG is refined from Natural Gas and is used by Light Trucks, Medium \& Heavy Trucks, and Transit Buses.

Liquefied Petroleum Gas (LPG):

$L P G$ is refined from Petroleum and is used by Light Trucks, Medium \& Heavy Trucks, and Transit Buses.

Gasoline:

Gasoline is refined from Petroleum and is used by Automobiles, Motorcycles, Light Trucks, Medium/Heavy Trucks, Transit Buses, Intercity \& School Buses, General Aviation, and Recreational Boating.

Jet Fuel:

Jet Fuel is refined from Petroleum and is used by General Aviation and Commercial Aircraft.

Diesel \& Distillate Fuel Oils:

Diesel \& Distillate Fuel Oils are refined from Petroleum and are used by Automobiles, Light Trucks, Medium \& Heavy Trucks, Transit Buses, Intercity \& School Buses, Passenger Rail, Freight Rail, Recreational Boating, and Commercial Shipping.

Residual Fuel Oil:

Residual Fuel Oil is refined from Petroleum and is used by Commercial Shipping.

\section{Energy Use:}

Light-duty vehicles

Light duty vehicles include motorcycles, automobiles, and light trucks.

Automobiles

The energy used by Automobiles is calculated as the sum of flows from Electricity Production, Ethanol, Biodiesel, Hydrogen, CNG, LNG, LPG, Gasoline, and Diesel \& Distillate Fuel Oils.

Motorcycles

The energy used by Motorcycles is equal to the flow from Gasoline. 


\section{Light trucks}

The energy used by Light Trucks is calculated as the sum of flows from Ethanol, Gasoline, and Diesel \& Distillate Fuel Oils.

\section{Medium \& Heavy Trucks}

The energy used by Medium \& Heavy Trucks is calculated as the sum of flows from Gasoline and Diesel \& Distillate Fuel Oils.

\section{Transit Buses}

The energy used by Transit Buses is calculated as the sum of flows from Electricity Production, CNG, Methanol, LNG, LPG, Gasoline, and Diesel \& Distillate Fuel Oils.

Intercity \& School Buses

The energy used by Intercity \& School Buses is calculated as the sum of flows from Gasoline and Diesel \& Distillate Fuel Oils.

Pipeline

The energy used by Pipeline is calculated as the sum of flows from Electricity Production and Natural Gas Refining.

\section{General Aviation}

The energy used by General Aviation is calculated as the sum of flows from Gasoline and Jet Fuel.

\section{Commercial Aircraft}

The energy used by Commercial Aircraft is equal to the flow from Jet Fuel and includes activities for domestic and all international air carriers.

\section{Passenger Rail:}

The energy used by Passenger Rail is equal to the flow from Diesel \& Distillate Fuel Oils and includes both transit, intercity, and commuter rail operations.

Freight Rail:

The energy used by Freight Rail is equal to the flow from Diesel \& Distillate Fuel Oils.

Recreational Boating:

The energy used by Recreational Boating is calculated as the sum of flows from Gasoline and Diesel \& Distillate Fuel Oils.

\section{Commercial Shipping:}

The energy used by Commercial Shipping, also referred to as Vessel Bunkering, is calculated as the sum of flows from Diesel \& Distillate Fuel Oils and Residual Fuel Oil and includes fuel use for both domestic and international activities. 